\title{
Small Courtyard Level and Vertical Landscape Design Research
}

\author{
Kang Xiao \\ Jiangxi Polytechnic College, Pingxiang, Jiangxi,China, 337055 \\ $353852890 @ q q . c o m$
}

Keywords: Small courtyard; Horizontal landscape; Vertical landscape; Design

\begin{abstract}
New era's change and development make more and higher requirements for small courtyard. Everyone's aesthetic view is different. Small courtyard style can reflect the subjectivity and aesthetic temperament interest of owner, and the design of small courtyard is the tool and premier to put the idea into reality. Small courtyard design in horizontal direction is to define the small courtyard in two-dimensional space. Different levels of landscape, such as lawn, plants, water, roads, road teeth, can create a different landscape effect accordingly. And the small courtyard in vertical landscape shapes three-dimensional space, and more easy to give a person a kind of deep impression on vision than horizontally. In design process, the owners and designers need to consider small courtyard's ambience and vertical landscape style, characteristics, highlight the key, and reasonably choose the collocation of vertical landscape and horizontal landscape.
\end{abstract}

\section{Introduction}

With the development of our country economy and the improvement of people's living standard, it is no longer a dream for people to have their own small home and family garden. Small courtyard has gradually gone into the lives of many people. Although many people have a small family garden, they don't know how to deal with it, and how to obtain scenery outdoor environment. Small courtyard design, construction, and gardening make its indoor decorate a perfect outdoor space, which is the owners' common wish, and it can make people get a kind of entertainment and spiritual enjoyment in the process of design. Therefore, small garden design, and construction have a broad market consumption potential, and has become a popular pastime of many people.

\section{The Basic Principle and Layout of Small Courtyard Design}

\section{A. Small courtyard design principle}

Everyone's aesthetic view is different. Small courtyard style reflects the subjectivity and aesthetic temperament and interest of owner. The design of small courtyard is the tool and premise condition to put the idea into reality [1]. Small garden design needs to learn the basic principles of small courtyard design in order to design a beautiful, practical small courtyard. First of all, a lot of small yards are of certain function, therefore, before design, a survey of the functional requirements is needed by a family members to understand the requirements of relevant issues. For example, what does the whole family like on architectural styles, materials, or plant, his way of life, the owner's outdoor entertaining needs, how many people do they treat, BBQ or cooking in the courtyard, outdoor recreation and sports activities, and do they like gardening? In understanding needs, determine the functions of the small courtyard, and then scientifically differentiate functional partitions, make each partition space not only meet functional requirements, but not interfere with each other, and work in harmony with the environment.

In addition to meet the needs of the function, small garden design also must consider courtyard form of beauty and the formation of a specific style [2]. Small courtyard beautiful form can put people spiritual beauty feeling into objective forms, letting a person happy and joyful and have settled mood. To form beautiful form and style, a small courtyard should strive for overall consideration of a few principles in the design: the oneness on space and time; partial and whole coordination; a certain 
element refining or strengthening method reasonable use; pay more attention to the unity of change and rhythm; scientific arrangement of suitable proportion and actual situation contrast, etc.

B. Small courtyard art layout

Small courtyard style is embodied in art layout. In today's gardens, although there are many kinds of garden style, such as Japanese style garden, Italian garden, modern garden, Suzhou garden, etc., there are also gardens refraining from particular styles. Regardless of what kind of style, garden needs to pay attention to its art layout. In general, the layout of small courtyard has the following kinds: rule type layout, natural type layout and deconstruction style [3], and the main characteristics of their respective analysis details are in Table 2.1. In the layout scene setting, whether using selected methods of landscape, landscape or borrow scene, illusion, all must consider the static space layout and dynamic space organization, pay attention to artistic unity of coordination and variability, and highlight the changes in the level and add suspense, mystery and a pleasant surprise to people.

Table 2.1 Layout form and its main features of small courtyard design

\begin{tabular}{|c|c|l|}
\hline Serial & $\begin{array}{c}\text { Small garden design } \\
\text { layout }\end{array}$ & \multicolumn{1}{c|}{ Main features } \\
\hline 1 & Rule type layout & \multicolumn{1}{c|}{ Given priority to balance and symmetry } \\
\hline 2 & Natural flow line & $\begin{array}{l}\text { Give priority to smooth lines, weaken the depressive feeling of } \\
\text { original boundary }\end{array}$ \\
\hline 3 & Deconstructive style & $\begin{array}{l}\text { Break the existing outdoor design rules, and put them back } \\
\text { together with abstract pattern } \\
\text { Back together }\end{array}$ \\
\hline
\end{tabular}

\section{Small Courtyard Horizontal Landscape Design Research}

Small courtyard horizontal direction design is to define the yard in two-dimensional space. Different levels of landscape, such as lawn, plants, water, roads, road teeth, can create a different landscape effect.

A. Small courtyard plants design factors

Small courtyard elements include lawn and ground cover plants.

(a) Lawn. Lawn is one of the most common ground-cover plants, which can provide comfortable surface for pedestrian walk, also provide a good rest for our eyes. Design of lawn can be rules, or no rule type. For small courtyard, irregular shape of lawns rich life and are full of change, but in the curved place, they should be smooth in order to trim. Lawn should also be designed according to use purpose and appearance.

Table 3.1 Various lawn design form and its effect analysis

\begin{tabular}{|c|c|l|}
\hline Serial Number & Lawn form & Lawn effect and characteristics \\
\hline 1 & Flat type lawn & $\begin{array}{l}\text { neutral floor material, exquisite and smooth like a carpet, } \\
\text { easy to be seamlessly integrated shape with smooth ground }\end{array}$ \\
\hline 2 & Smooth lawn & Surface smooth, flawless, appropriate rest and exercise \\
\hline 3 & Fancy lawn ornament & Daisy or wild flowers, natural ecological breath \\
\hline 4 & Long length grass lawn & $\begin{array}{l}\text { Adequate grass length, wind ripples with aesthetic feeling } \\
\text { and movement }\end{array}$ \\
\hline
\end{tabular}

Climate, soil type and curing conditions are chosen for appropriate grass seed. Table 3.1 shows design of various lawn forms and performance results. 
(b) Cover plant. Cover plant is plant covered on the surface, which should be considered in small garden design. Cover plants are generally suitable for planting in these places: on the slopes where people rarely do activity to maintain water and soil; or plant in places of poor conditions, such as sands, soil ridges, more thin, inadequate, and dark, without sun, or strong wind place; or parts which are not allowed to trample on, both sides of the street to define space; or there is a need to foil other scenery, etc.

B. Small courtyard pavement design

Small courtyard hinterland form connected dominated transportation network of a line or plane formation, which adjunct space and contact space, and are the main landscape elements in botanical garden landscape [4]. The function analysis is shown in Figure 3.1. The floor materials are many, generally in two types: inorganic materials and organic materials. Designers need to consider the overall atmosphere, the characteristics of houses and walls and other building materials of small courtyard and the coordination with surrounding environment, fully understand the properties of pavement material and pavement effect to choose material and lay the ground. Commonly used pavement types and their respective characteristics in design are analyzed as follows:

(a) Soft pavement. Loose stones aggregate and form soft pavement, which can disperse vehicle and pedestrian traffic. There are many kinds of types in soft pavement, and each type is of flexible pavement properties and different effect. Although simple, gravel road size and shape are irregular, it has the style of natural of primitive simplicity, and its permeability is also very good. And coconut shell fragments and bark, as paving materials, have irregular appearance, and can let a person find everything new and fresh. Coconut shell fragments have close ties to bark and tree, which are often used to compare deserted place or forest region, and its delicate texture at the same time gives a person a kind of comfortable feeling. But the boundary of the pavement surface of coconut shell fragments and bark generally uses logs to keep the natural appearance and surface consistency.

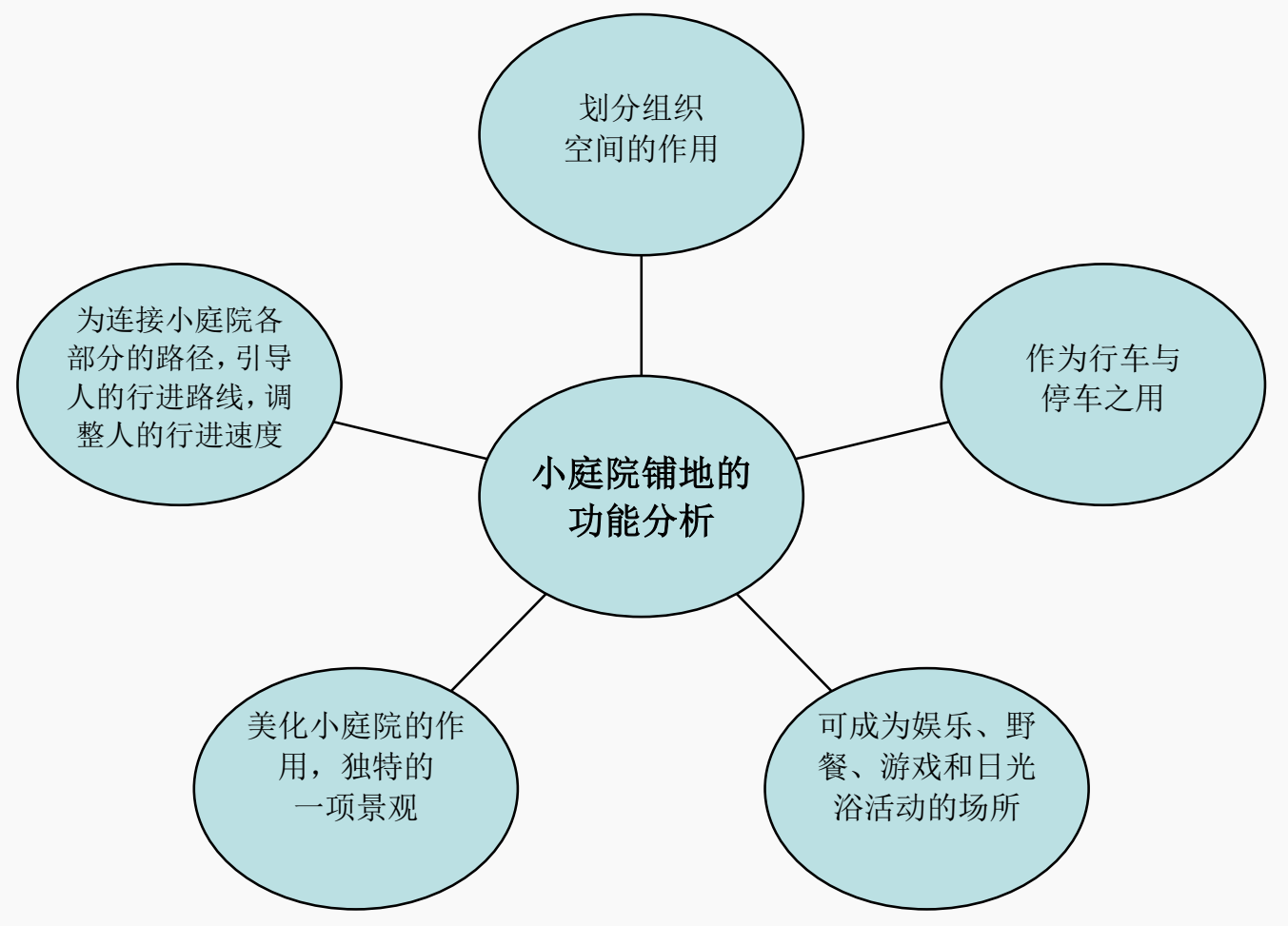

Figure 3.1 Function analysis diagram of small courtyard floor

(2) Rigid pavement. Pour concrete foundation, and on the foundation, lay a layer of mortar. This new material is not porous solid platform, and this is rigid pavement. Material selection of rigid pavement design should also pay attention to the method of lying to reflect their different appearance. Every kind of laid method should be selected based on the analysis of features of the small courtyard, 
the use of material properties, cost, and functions. For example, using the basic present natural stone with arbitrary rectangular laid method, "ice crack" can be formed.

Laying on the ground with smooth, firm cobble can produce a kind of beautiful, delicate and complex pattern; And use artificial stone or marble to lay a curved path design can guide pedestrian road direction, and show comfortable, optional features, by reducing hard pavement the feeling of rigid and constraint, which is shown in Figure 3.2.

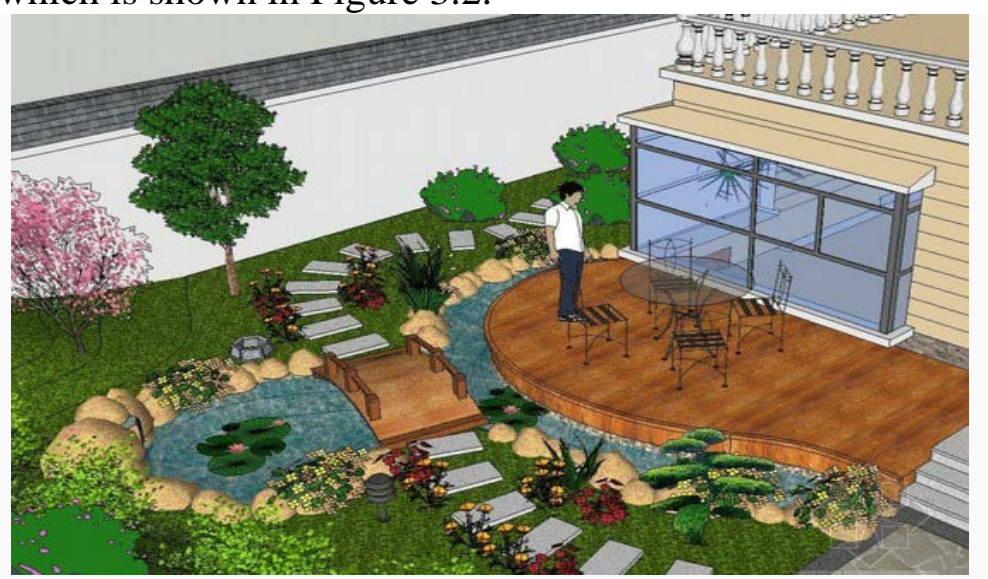

Figure 3.2 Winding paths marble floor pattern of family small courtyard

In addition to the above introduction of small yard ground pavement types, there are other materials organization ground pavement, such as brick, wood, resin, rubber materials, concrete brick, straw, and mix material. Mixed pavement is a kind of creative design; the landscape is unique, and the sense gives a person shine at the moment. It can divide a large surface area into small pieces of ground according to different levels, with relative geometry designed of two materials as a main body, such as bricks with sandstone, tiles and pebble; it embodies the designer's design intention, and is extremely attractive.

C. Small courtyard horizontal landscape design method

Small courtyard generally belongs to individual family with not very big area, but with elaborate design and organization construction, it may achieve a more perfect effect. The landscape is not a very smart, but it is an important part of small courtyard design idea and effect. Small courtyard landscape design should first play horizontal landscape important guiding role in lane, and ground cover (such as lawn) functions, that is to put the function of horizontal level of landscape design considerations as the first thing to do, and there is no need to deliberately stiffly build a path, which will give people the impression of a gild the lily. At the same time, horizontal landscape design also must insist to give a person a kind of visual aesthetic effect. For example, from visual point of view, the design of tooth can greatly strengthen the paving effect of path and luxury decorative road, but bricks to $45^{\circ}$ inclined soil forming teeth would be more ornamental, and reflects a trace of designer pursuing exquisite and beauty.

\section{Iv. Small Courtyard Vertical Landscape Design Research}

Change and development of the new era make more requirements for small courtyards. Small courtyard is gradually getting into the homes, at the same time, people need it both meet use function, but let people have a sense of physical and mental pleasure, and cultivate people's sentiments. In history, our country garden values flat landscape and the selection of low landscape, often through "view" design technique to reflect Chinese traditional culture of "humility", "cultivate one's morality", "quiet" personality and moral character [5]; In the new era's reform and opening up trend, a number of times players take in western gardens sculpture, flower beds, fountains and courtyard landscape construction concept, and dare to pursue small courtyard's own style to make the small courtyard fully reflect owner's personality. This outstanding reflects in small garden vertical landscape design and construction. Because vertical landscape shapes three-dimensional space, on the vision it is more 
obvious than horizontal landscape, and is more easy to give a person deep impression. Small courtyard vertical landscape is various, trees , herbaceous plants, flower beds and rockery, green fence, fences, walls, sculpture, fountains, gallery building and so on. Here we discuss two vertical landscape designs.

A. Small garden fence design

Fence materials used in small yard include metal, plastic, bamboo, concrete, but the most widely used is wood. Fence can protect plants from illegal invaders and livestock persecution, and can also be weather-proof, increase illicit close space. When design, choose the right fence based on the characteristics and performance of all kinds of fence effects. As is shown in Figure 4.1, the design of pointed wattle fence can independently develop a landscape, and raise the spectra of miss and yearning rural life.

B. The design of small courtyard flower bed

Small courtyard planting is highly ornamental plant, and plant materials can be divided into: biennial herbaceous flower, perennial root flowers, bulbous flowers, five-color grass, and mixing plant. According to flower bed space position, the design of flower bed types can be divided into: plane flower bed, flower bed, slope bed, steps bed, multi-layer flower bed and overlooking flower bed [6]. Various factors should be considered in the design of flower bed, and the key influencing factors are:

(a) Relationship with flower bed and environment. Design must make color, form, theme and so on be in harmony with the environment, particularly with surrounding buildings, roads, and plants, which is shown in Figure 4.2.

(b) Color processing. Design should pay attention to all sorts of color's number, proportion, light and shade, the application of contrast color, the use of color in the middle, the use of warm and cool colors and the relationship between environment and color, etc.

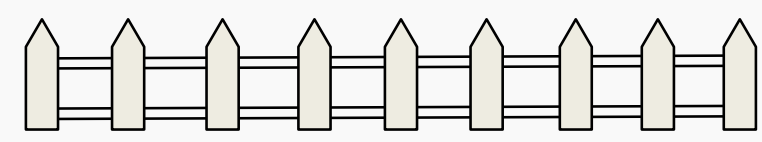

Figure 4.1 Pointed slatted wooden fence

(c) Flower beds level and background. Commonly in design, we adopt high outside and low inside to make the form of low cant bed naturally, which is advantageous for observers see flower bed in clear view and pattern, so we also need to combine the background of the flower bed located and flower bed itself together.

(d) Flower bed plants. We can use different blooming flowers to make the whole view of flower bed time relatively longer, and achieve the goal of reducing flower bed replace number, in order to reduce owners time, effort and cost.

C. Small landscape vertical garden design

Modern garden technology research show that the smaller the small courtyard, more prominent its vertical landscape effect is. In the design of small courtyard vertical landscape, considering small courtyard relatively small space, we should consider more vertical landscape effects of landscape elements, highlight its landscape function; at the same time, highlight the design of key landscape, such as: a rockery, a sculpture, etc., as the main body and key of vertical landscape. In the process of design, the owners and designers need to consider the small courtyard ambience and whether the style and characteristics of vertical landscape are in harmony with the surrounding atmosphere, reasonably choose a vertical view of subjectivity. But not blindly, pile vertical landscape too much, otherwise it will make a small courtyard a bloated, contradiction, mixed and disorder feeling, and is not conducive to form a comfortable, pleasant small courtyard style. In addition, when designing small courtyard vertical landscape, play its another important role, which is the design and use of water, fountains, fish pond and vertical landscape (as shown in Figure 4.3), and make the stillness of courtyard landscape more of activity, changing scenery, so that it can greatly increase the vitality and appeal of small courtyard so as to show a small courtyard's own vitality. 




Figure 4.2 Part of design and construction of flower bed

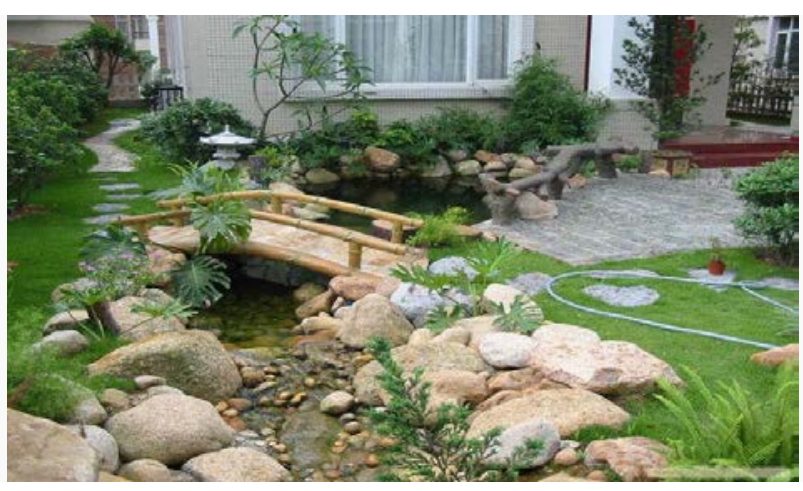

Figure 4.3 Small courtyard small bridge , flowing water landscape

\section{References}

[1] Niu Zehui. Small courtyard vertical landscape construction [J]. Journal of Flowers and Trees Bonsai (Flower Gardening) 2005,07.

[2] Wang Yongbin. Theory of small courtyard design [J]. Science, Technology and Business. 2011, 10.

[3] Wu Yueye. Garden landscape design research based on local culture [D]. Northwest Agriculture and Forestry University of Science and Technology. 2010, 05.

[4] Li Xiaobo. Courtyard landscape design research [D]. Hebei Agricultural University. 2013, 05.

[5] Chen Chi. Modern villa landscape courtyard design research [D]. Hunan Agricultural University. 2013,05.

[6] Xu Feng, Liu Ying, Niu Zehui. Garden landscape design and construction [M]. Beijing: Chemical Industry Press, 2006, 3. 